\title{
LAS ENSEÑAS Y UNIFORMES DE LOS ESPAÑOLES EN FILIPINAS
}

\section{LESSONS AND UNIFORMS OF SPANISH IN THE PHILIPPINES}

\section{AUTOR}

\section{José L. Rodríguez Lizcano}

Escritor de varios artículos en revistas científicas y divulgativas (España)

rodríguezleizcano@hotmail.com

\section{RESUMEN}

Artículo en el que describe cuál fue la identidad de las tropas españolas durante la guerra de independencia de las Filipinas. Explica qué enseñas, banderas y vestimenta utilizó el ejército para tener su propia identidad en el conflicto. También se explica cómo fue el avance de las Unidades Españolas en el territorio filipino y qué medios fueron utilizados para llevar a cabo tal proceso.

\section{PALABRAS CLAVE}

Uniformes - Organización - Enseñas - Filipinas - Unidades Españolas - Identidad

\section{ABSTRACT}

Article that describes what was the identity of the Spanish troops during the War of Independence of the Philippines. Explain what you teach, flags and clothing used the army to have its own identity in the conflict. It also explains how it was the advance of Spanish units in the Philippine territory and what means were used to carry out such a process. 


\section{KEY WORDS}

Uniforms - Organization - Education - Philippines - Spanish units - Identity.

\section{ÍNDICE}

1. Antecedentes históricos. Del "libro de bolsillo" a las "escalillas" (1760-1940).

2. Las primeras expediciones al "País de Ma-yi", la I sla de "Leyte" o "Filipina".

3. El ejército de ultramar. Las tropas de los presidios.

4. Banderas y estandartes del ejército español en Filipinas.

5. La uniformidad de las unidades en Filipinas.

6. Curiosidades de Filipinas. El transporte de agua.

7. Bibliografía.

Existe un particular propósito que nos ha movido a acometer la investigación, el dibujo y la difusión de las Enseñas o Banderas, Organización y los Uniformes de las Unidades Españolas que lucharon en las Islas Filipinas.

Las figuras e ilustraciones (vestidas, armadas, y ambientadas), responden por razones de Editorial, a una sencilla pero esmerada selección y/o aproximación de algunas Armas y Cuerpos, intentando presentar como perspectiva de la época, una variedad que amalgame los diferentes tipos de Banderas y Estandartes, y la evidente vistosidad de los Uniformes (añadiendo alguna anécdota curiosa), sin llegar a ser en ningún momento rigurosos en los detalles.

Para mayor claridad de exposición y concretar algunas diferencias en el vestuario, la Sociedad Española de Estudios de la Comunicación Iberoamericana -SEECI- ofrecerá 


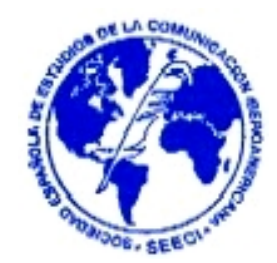

en próximos boletines, un amplio y detallado Glosario de Términos, no empleando por tanto en el presente palabras excesivamente técnicas.

\section{Antecedentes históricos. Del "Libro de Bolsillo" a las "Escalillas" (1760-1940)}

Los datos de las primeras ediciones de la Guía de Forasteros de Madrid, a modo de librito de bolsillo editado en 1760 durante el reinado de Carlos III, ofrecían de forma muy escueta los primeros datos con los nombres y antigüedad de los Regimientos, así como una relación de sus mandos más importantes.

Pasados unos años, en 1768, adquirió mayor importancia tomando el nombre de "Estado Militar de España" ampliándose los datos a Europa, África, América y Filipinas, y detallando (aunque carente de iconografía) una valiosa y fiable fuente en cuanto a organización, plantillas y uniformes, alcanzando una publicación anual.

De forma paralela existieron otras publicaciones semejantes como la Guía Oficial de España (1787) y el Kalendario Manual y Guía de Forasteros, con ediciones en Barcelona (1806), Guatemala (1807), Venezuela (1810) y Manila (1833).

Posteriormente se fueron ampliando las relaciones de todos los componentes de las Armas en publicaciones como el Estado de Ingenieros (1838) o el Escalafón de Artillería (1845), para dar paso en 1892 a los Anuarios, posteriormente titulados Escalillas (1940), en las que se ofrecen análogas referencias ampliamente extendidas.

\section{Las primeras expediciones al "País de Ma-yi", la Isla de "Leyte" o "Filipina".}

La presencia de España en Filipinas comenzó cuando en Marzo del año 1521 los españoles de la expedición a la isla de las Especias, que acompañaban al heroico 


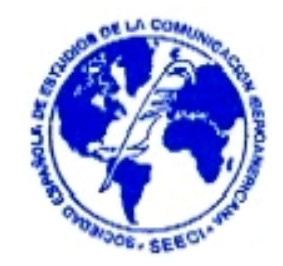

navegante Magallanes, avistaron las tierras del País de Ma-Yi, al que bautizaron como San Lázaro, celebrando en Butúan (Isla del país de las lagunas) la primera misa, llegando a alcanzar la mayor gloria al servicio de la Católica Majestad del Rey de las Españas.

La expedición de Rui López de Villalobos llegó a Mindanao el 2 de febrero de 1553 y bautizó la isla de Leyte con el nombre de "Filipina". Muy pronto este nombre se extendería a San Lázaro o Islas de Poniente, dando lugar a la definitiva denominación del archipiélago: Filipinas.

El Rey Felipe II dió la orden de ocupar aquellas tierras, y un 21 de Noviembre del año 1564 Miguel López de Legazpi con 200 soldados, 150 hombres de mar y 5 religiosos agustinos zarpó del Puerto de Navidad en México, alcanzando el 13 de febrero del siguiente año las Filipinas.

La importancia de estas islas venía señalada por ser un punto intermedio en la ruta de la seda, de las especias y de las maderas exóticas, y próximo al continente asiático por lo que fueron objetivo de gran importancia estratégica para holandeses e ingleses. Tanto unos como otros realizaron acciones sobre el archipiélago, que fueron realizadas por los españoles y el apoyo solidario de los filipinos.

\section{El ejército de ultramar. Las Tropas de los Presidios.}

La historia del Ejército de Ultramar es la historia de la Infantería de aquellos territorios, pues el grueso de las tropas que allí existieron eran del Arma.

Durante el siglo XVI, a medida que se desarrollaba la colonización, se fue estabilizando la exploración y conquista de los territorios. Hubo que defenderlos de los ataques de los indios no sometidos, y muy especialmente en el interior. De igual manera hubo que establecer en las costas un sistema defensivo que protegiese los puertos y las mercancías que periódicamente se enviaban a la península. 
La defensa del interior corría a cargo de los propios colonos que se movilizaban cuando la ocasión lo requería. Todo ello dio lugar a la creación de "milicias locales" o "gremiales", a cargo de algún soldado veterano con la misión de instruirlas.

Durante los siglos XVI y XVII no existió de forma regular una guarnición de tropas en los territorios, salvo pequeñas unidades como guardia personal de seguridad para altos dignatarios.

En el reinado de Felipe V (terminada la Guerra de Sucesión), se crearon "Unidades Fijas" para la defensa de las zonas más importantes, pues las antiguas "milicias" ya no resultaban eficaces, comenzando el envío regular de unidades peninsulares, de los que con el paso del tiempo sólo alcanzaban a regresar unos cuantos oficiales y soldados. Esta fue la manera en la que se configuró un ejército "extrapeninsular" de cierta entidad, hasta bien entrado el siglo XVIII.

Fueron organizadas a partir de las instrucciones que pusieron en práctica el Conde de Ricla y D. Alejandro O'Reilly en Cuba y Villalba en Nueva España (1765), donde tenían cabida todo tipo de individuos, sin distinción de raza ni color, pero casi siempre separados unos de otros. Así, hubo regimiento de "Blancos", de "Pardos", de "Morenos", e incluso, Regimiento de "todos los colores".

Destacaremos cinco categorías distintas: el "Ejército de Dotación", las "Tropas de los Presidios", las "Tropas Peninsulares de Refuerzo", las "Milicias Regladas 0 Provinciales" y, por último, las "Milicias urbanas" o "locales".

Las "Tropas de los Presidios" o "compañías presidiales" tenían por objeto rechazar los ataques de los indios contra los sentamientos, misiones o explotaciones mineras. Estaban compuestos por unidades un tanto "especiales" de infantería, caballería y en ocasiones artillería. Desde 1772 convertidas en "unidades distintas" al resto del Ejército y las Milicias. 


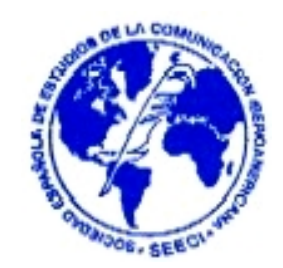

El Reglamento e Instrucción para los Presidios internos que se formaron en la frontera de la Nueva España, cita en sus artículos 5ㅇ y 6이 lo siguiente:

“... que estas fuerzas, aunque tengan distintas plantillas, organización y uniformidad que el resto del Ejército, tengan las consideraciones de tropa veterana y esté sometida a las Ordenanzas Generales del Ejército."

\section{Banderas y estandartes del ejército español en Filipinas}

Las enseñas constituyen los elementos más importantes de identificación y por ello no podían quedar sin una referencia, aunque breve.

Las Ordenanzas Generales fechadas el 22 de octubre de 1768, reinando felizmente nuestro Rey Carlos III, referían en su Título I, artículo 10ํa a las Banderas, que eran las "enseñas" usadas por las Tropas a pie.

Las había de dos clases, la "Coronela", blanca con el escudo de las Armas Reales, y las de los "Batallones", blanca también, con la Cruz de Borgoña en Rojo; y en las esquinas o extremos de ambas, las armas o escudos de donde tomasen su denominación los Regimientos.

Estaban confeccionadas en tejido liviano, pintadas, con telas superpuestas 0 bordadas con hilos de seda, y con astas de 8 pies y 6 pulgadas $(237 \mathrm{~cm}$.) y telas de 7 cuartas en cuadrado $(146 \mathrm{~cm}$.)

Los Estandartes, eran las insignias de las unidades montadas, de los que habría uno por Escuadrón, llevando todos ellos, en el reverso, el escudo del Regimiento.

La Caballería y los Dragones los tuvieron rojos, blancos, azules y amarillos. Estaban confeccionados de damasco o terciopelo, carmesíes, azules o blancos, bordados en 


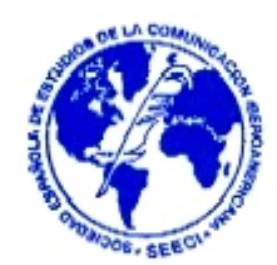

oro o plata y sedas de colores. Los de Caballería medían 2 pies en cuadro $(56 \mathrm{~cm}$.) y los Dragones 2 pies de alto y el largo terminaban en dos farpas con puestas a 2 pies y una cuarta $(70 \mathrm{~cm}$.) con entrante a dos cuartas $(40 \mathrm{~cm}$.)

\section{La uniformidad de las unidades en Filipinas.}

La ocupación del archipiélago se realizó, en todas sus épocas, con muy pocos hombres y a pesar de las frecuentes rebeliones y algaradas, siempre salieron airosos los españoles. Sirve de ejemplo el dato de que en Abril de 1609, sólo había cinco compañías al mando del Gobernador D. Juan de Silva.

Nos presenta la figura de un Cabo 20 de Tropas Veteranas de Filipinas. Su uniforme, de campaña y como tropas ligeras, consistía en: casaca azul; collarín, vuelta y solpa encarnados; cartera, vivo, forro, chupa y calzón blancos; en la vuelta de la bocamanga dobla en forma de martillo de tres lises y botón dorado. Los naturales para campaña tocados con el "rotín", sombrero hecho de briznas de bambú, y descalzos; el fusil es de 1780 para tropas ligeras; la cantimplora es un trozo de tronco de bambú.

El Regimiento (del Rey) y los dos Batallones de Tropas Veteranas de Filipinas (de la Reina María Luisa y del Príncipe Fernando), vestían igual.

El cambio de Tercio a Regimiento, no se produjo en Filipinas hasta 1754, creando uno con el nombre de "Rey", desaparecido tras la pérdida de Manima en 1762, y reorganizado dos años más tarde, cuando se recuperó la plaza. Como dato curioso, decir que en 1755, de los 1.264 hombres del Regimiento del Rey, 859 eran filipinos, 298 americanos y 107 europeos. Posteriormente, a partir de 1790, se crearon las "Milicias Provinciales de Infantería", con los "Regimientos de Mestizos" siguientes: del "Real Príncipe", de "Cagayán", de "Pangasinan", de "Bulacan", de "Camerines", de "Batangas" y de "Pampanga".

Las embarcaciones utilizadas por los Filipinos se llamaban "batangas", construidas 


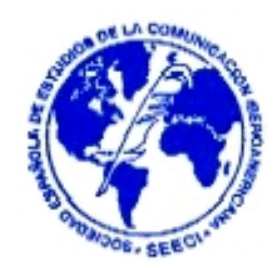

con hojas de palma trenzadas o con troncos de árboles ahuecados. Tenían un sólo "batango" o marinero, que se servía de un único remo corto y de pala ancha. Se le denominaba "banquero", sin duda por que faenaba en aguas poco profundas con bancos de arena o cieno.

Las tropas vestían habitualmente el uniforme de campaña, que era azul, al principio de mahón y luego de guingón. Los soldados se cubrían la cabeza con un capacete de palma o "bejuco", y por imponerlo la costumbre y la conveniencia, iban descalzos.

Hasta 1857 no empezaron los uniformes azules a ser sustituidos por los de "rayadillo". El primer Cuerpo que lo usó fue la Infantería de Marina, que tuvo un pantalón de este tejido para faena anterior a esta fecha. En 1861 se reguló una "levita de rayadillo" para oficiales del Cuerpo de Guardias de Arsenales, y posteriormente la reglamentación de estos uniformes se extendió a casi todas las Unidades de Ultramar.

Según una descripción más ajustada de estos uniformes en la Guía de Forasteros de las Islas Filipinas del año 1860, los cita así: casaca corta azul, con collarín, barras, portezuelas de las mangas y vivos encarnados, botón convexo, guante de punto de algodón blanco, morrión con escudo y carrilleras de latón, franja de estambre encarnado en los Granaderos y Fusileros y verde los Cazadores, con el número del Regimiento en el botón y galleta, pantalón blanco, zapato abotinado, y para media gala y diario, casaquín blanco.

\section{Curiosidades de Filipinas. EI Transporte de Agua.}

Se trata de un carro con cuba o tonel utilizado en Filipinas para conducir el agua. Tenía dos ruedas, brazales terminados en varas, contralimones, teletas y cabezales. La cuba poseía un tapón roscado en su parte superior y un grifo en la base posterior; toda ella rodeada por ocho cinchas de hierro.

El tiro es un "carabao", mal llamado "búfalo filipino", un mamífero rumiante bastante 
extendido por Asia, Ceilán, India y especialmente Filipinas. Los "carabao" fueron domesticados desde muy antiguo para su empleo como bestias de tiro para transporte, para dominarlos se les colocaba un anillo de hierro en la nariz.

\section{Bibliografía}

ALÍA PLANA, Jesús María. El ejército español en Filipinas.

Archivo General de la Armada. Fondos documentales.

Archivo General de Indias. Signaturas Uniformes 60/62. Sevilla

Archivo Museo del Ejército (Madrid).

Archivo del Museo Oriental del Real Colegio de los Agustinos Filipinos (Valladolid).

Catálogo de publicaciones de la SEECI. Información y Comunicación Bibliográfica Especializada.

CLONARD, Conde de. Historia Orgánica de las Armas de infantería y Caballería Españolas. Madrid, 1858.

Guía de Forasteros en las Islas Filipinas para el año 1856. Hemeroteca Municipal de Madrid (AM 28/5-4315)

Historia de la Infantería Española. Editorial Espasa.

MANZANO LAHOZ, Antonio y GRÁVALOS GONZÁLEZ Luis. Los uniformes del Estado Militar de España del año 1895.

Revista General de Marina.

Revista El Mundo Militar. Panorama Universal. Madrid.

Uniformes militares del Ejército de Carlos III.

Uniformes Militares del Ejército de América y Filipinas. Ediciones del Ministerio de Defensa. 